\title{
Secretory Expression and Characterization of Two Hemicellulases, Xylanase, and $\beta$-Xylosidase, Isolated from Bacillus Subtilis M015
}

\author{
Alison L. Banka • Saadet Albayrak Guralp • \\ Erdogan Gulari
}

Received: 31 March 2014 / Accepted: 2 September 2014 /

Published online: 16 September 2014

(C) The Author(s) 2014. This article is published with open access at Springerlink.com

\begin{abstract}
Microbial hydrolysis of lignocellulosic biomass is becoming increasingly important for the production of renewable biofuels to address global energy concerns. Hemicellulose is the second most abundant lignocellulosic biopolymer consisting of mostly xylan and other polysaccharides. A variety of enzymes is involved in complete hydrolysis of xylan into its constituent sugars for subsequent biofuel fermentation. Two enzymes, endo- $\beta$-xylanase and $\beta$-xylosidase, are particularly important in hydrolyzing the xylan backbone into xylooligosaccharides and individual xylose units. In this study, we describe the cloning, expression, and characterization of xylanase and $\beta$-xylosidase isolated from Bacillus subtilis M015 in Escherichia coli. The genes were identified to encode a 213 amino acid protein for xylanase (glycoside hydrolase (GH) family 11) and a 533 amino acid protein for $\beta$-xylosidase (GH family 43). Recombinant enzymes were produced by periplasmic-leaky E. coli JE5505 and therefore secreted into the supernatant during growth. Temperature and $\mathrm{pH}$ optima were determined to be $50{ }^{\circ} \mathrm{C}$ and 5.5-6 for xylanase and $35{ }^{\circ} \mathrm{C}$ and $7.0-7.5$ for $\beta$ xylosidase using beech wood xylan and p-nitrophenyl- $\beta$-D-xylopyranoside as the substrates, respectively. We have also investigated the synergy of two enzymes on xylan hydrolysis and observed $90 \%$ increase in total sugar release (composed of xylose, xylobiose, xylotriose, and xylotetraose) for xylanase/ $\beta$-xylosidase combination as opposed to xylanase alone.
\end{abstract}

Keywords Hemicellulose $\cdot$ Xylan $\cdot$ Xylanase $\cdot \beta$-xylosidase $\cdot$ Xylooligosaccharides $\cdot$ Bacillus subtilis $\cdot$ Secretory expression $\cdot$ Escherichia coli JE5505

Alison L. Banka and Saadet Albayrak Guralp have equal contribution.

A. L. Banka $\cdot$ S. Albayrak Guralp $(\bowtie) \cdot$ E. Gulari

Department of Chemical Engineering, University of Michigan, 3074 H.H.Dow Buil.,

2300 Hayward St, Ann Arbor, MI 48109, USA

e-mail: saadetal@umich.edu 


\section{Introduction}

Concerns about greenhouse gases, a finite fossil fuel supply, and an increase in energy needs around the world has led to an increased interest in alternative fuel sources such as the use of lignocellulosic biomass for biofuel production [1]. Several groups employed metabolic pathway engineering tools to modify microorganisms to convert processed lignocellulosic biomass to a renewable fuel source such as ethanol, biodiesel, and isobutanol [2-5]. Lignocellulosic biomass consists of three major components: cellulose (30-50\% dry weight), hemicellulose (20-40\%), lignin (15-25\%), and ash and other components (3-10\%) [6]. While both cellulose and hemicellulose can be hydrolyzed to individual sugar molecules, hemicellulose's short, branched, non-crystalline nature makes it more ideal for hydrolysis than cellulose [7]. Hemicelluloses are comprised of several monosaccharide units, mainly xylan with lesser amounts of arabinan, galactan, and mannan, depending on the origin. The main hemicellulose of hardwoods and many agricultural crops is xylan, which is a linear polysaccharide consisting of D-xylose units linked by $\beta$-1,4-glycosidic bonds with a large variety of substitutions [8]. At least two enzymes, endo-1,4- $\beta$-xylanase (EC 3.2.1.8) and 1,4- $\beta$-xylosidase (EC 3.2.1.37), are required to hydrolyze the xylan backbone to individual xylose units, with additional enzymes required to cleave any side groups [9]; this hydrolysis allows an organism to use hemicellulose as a food source, providing xylose to be utilized as a sugar source [10].

Many xylanases have been previously isolated and characterized from different strains of bacteria and fungi [11-13]; $\beta$-xylosidases and the co-activity of two enzymes on xylan hydrolysis however have been described to a lesser degree [14-16]. In this study, we have cloned two genes coding for endo-xylanase and $\beta$-xylosidase from a recently-isolated strain Bacillus subtilis M015 and strategically expressed them in a periplasmic-leaky Escherichia coli strain which resulted in successful secretion of the recombinant proteins outside of the cells at high levels. The two enzymes were characterized separately, and both their individual and combined effect on hydrolysis of beech wood xylan was examined. Secretory expression of endo-xylanase and $\beta$-xylosidase allows them to be readily available in culture supernatant and continuously hydrolyze xylan into xylose and other xylooligosaccharides which can be consequently utilized by an engineered fuelproducer strain to generate biofuels.

\section{Materials and Methods}

\section{Microbial Strains and Plasmids}

B. subtilis M015 was previously isolated from Thai higher termites, Microcerotermes sp., [17] and provided by Professor Sumaeth Chavadej's Lab at the Petroleum and Petrochemical College at Chulalongkorn University in Bangkok, Thailand. E. coli JE5505 (carrying an lpp-deletion) was obtained from The Coli Genetic Stock Center (CGSC) at Yale University and the plasmid pFLAG-CTS was purchased from Sigma-Aldrich.

\section{Chemicals, Substrates, and Media}

B. subtilis M015 was grown in tryptic soy broth (TSB), and E. coli JE5505 was maintained in lysogeny broth (LB). $p$-nitrophenol ( $p$ NP) and $p$-nitrophenyl- $\beta$-D-xylopyranoside (pNPX) were purchased from Acros Organics and Calbiochem, respectively. Xylooligosaccharides 1,4- $\beta$-D-xylobiose, 1,4- $\beta$-D-xylotriose, and 1,4- $\beta$-D-xylotetraose (Megazyme) were provided 
by Professor Xiaoxia Lin's Lab (University of Michigan) to be used as standards (X1 to X4) for high-performance liquid chromatography (HPLC).

\section{Cloning and Expression of Recombinant Endo-Xylanase and $\beta$-Xylosidase}

The following two primers were used for the amplification of the xylanase gene by polymerase chain reaction (PCR) using B. subtilis M015 genomic DNA as the template: forward primer (HindIII) 5'-CAGGATCCAAGCTTCTATGTTTAAGTTTAA AAAGAATTTCT-3', reverse primer (EcoRI) 5'-GCTCAGAATTCTT ACCACACTGT TACGTTA-3'. The xylanase gene was amplified using Phusion High-Fidelity DNA Polymerase (New England Biolabs) with the following PCR program $7 \mathrm{~min}$ at $98{ }^{\circ} \mathrm{C}$, $30 \mathrm{~s}$ at $98{ }^{\circ} \mathrm{C}, 30 \mathrm{~s}$ at $53{ }^{\circ} \mathrm{C}$, and $30 \mathrm{~s}$ at $72{ }^{\circ} \mathrm{C}(33$ cycles $)$, and $5 \mathrm{~min}$ at $72{ }^{\circ} \mathrm{C}$. Amplification of the $\beta$-xylosidase gene was performed similarly using the following primers: forward primer (Xhol) 5'-GTACTCGAGAAATGAAGATTACCAATCCC-3' and reverse primer $(E c o R I)$ 5'-GCCGAATTCTTATTTTTCTTTATAACGAAAATATC3 '. Both primer sets were designed based on the sequence of xylanase $(x y n A)$ and $\beta$ xylosidase $(x y n B)$ genes of $B$. subtilis 168 (GenBank accession number; AL009126.3). Standard molecular biology techniques were performed for the purification, digestion, and ligation of the PCR products and the linearized plasmid DNA. Ligation products (pCTS-XynA and pCTS-XynB) were transformed into E. coli JE5505 by electroporation, and the cloning of the genes was confirmed by DNA sequencing.

For recombinant enzyme production, E. coli cells carrying either pCTS-XynA or pCTS-XynB were grown overnight in $2 \mathrm{~mL}$ LB-Ampicillin $(100 \mu \mathrm{g} / \mathrm{mL})$, and diluted $1: 400$ in $10 \mathrm{~mL}$ M9 minimal media containing $100 \mu \mathrm{g} / \mathrm{mL}$ ampicillin. Once the optical density of the culture reached $\mathrm{OD}_{600}=0.5$, gene expression was induced with $1 \mathrm{mM}$ of isopropyl- $\beta$-D-thiogalactopyranoside (IPTG, Invitrogen Life Technologies) for $16 \mathrm{~h}$ at $37{ }^{\circ} \mathrm{C}$. Next day, the cells were pelleted at $4{ }^{\circ} \mathrm{C}$ and clarified supernatant was sterilized using a $0.22 \mu \mathrm{m}$ filter. This supernatant was used as crude enzyme (visualized by sodium dodecyl sulfate-polyacrylamide gel electrophoresis) in the following activity assays.

\section{Enzyme Assays}

\section{Assay for Xylanase Activity}

Endo-1,4- $\beta$-xylanase activity was determined by the dinitrosalicylic acid (DNS) method [18]. Briefly, $1 \%$ beech wood xylan was dissolved in $50 \mathrm{mM}$ sodium citrate buffer at $\mathrm{pH} 6.0$ and incubated with diluted crude enzyme for $10 \mathrm{~min}$ at $50{ }^{\circ} \mathrm{C}$. An equal volume of DNS solution (1.4\% 3,5-dinitrosalicyclic acid, $0.28 \%$ phenol, $0.07 \%$ sodium sulfite, $28 \%$ sodium potassium tartrate, $1.4 \%$ sodium hydroxide) was added to each sample and incubated at $95{ }^{\circ} \mathrm{C}$ for $5 \mathrm{~min}$. The absorbance of the mixture was measured at $540 \mathrm{~nm}$, and amount of sugars released from xylan were calculated using D-xylose as a standard. The specific activity (IU/mL) of XynA is defined as the number of micromoles of xylose released per minute per unit volume of XynA crude enzyme. Relative activity of XynA for the temperature profile was determined by dividing the specific activity of XynA at a given temperature by that at $50{ }^{\circ} \mathrm{C}$. The relative activity of $\mathrm{XynA}$ for the $\mathrm{pH}$ profile was determined by dividing the specific activity at a given $\mathrm{pH}$ by that at a $\mathrm{pH} 5.5$ in sodium citrate buffer. 
Assay for $\beta$-Xylosidase Activity and End-Product Inhibition by Xylose

$1,4-\beta$-xylosidase activity was assessed by "pNPX assay" through incubation of the crude enzyme in $50 \mathrm{mM}$ sodium phosphate buffer at pH 7.0 with $5 \mathrm{mM}$-nitrophenyl- $\beta$-Dxylopyranoside (pNPX) in buffer. The incubation took place at $40{ }^{\circ} \mathrm{C}$ for $10 \mathrm{~min}$ in a VersaMax microplate reader (Molecular Devices) measuring absorbance at $410 \mathrm{~nm}$ every $15 \mathrm{~s}$. The specific amount of $p$-nitrophenol (pNP) released was calculated using pNP standards at varying concentrations. The specific activity $(\mathrm{IU} / \mathrm{mL})$ of $\mathrm{XynB}$ is defined as the micromoles of pNP released per minute per unit volume of XynB crude enzyme. Relative activity of XynB for the temperature profile was determined by dividing the specific activity of $\mathrm{XynB}$ at a given temperature by that at $35{ }^{\circ} \mathrm{C}$ and the relative activity of $\mathrm{XynB}$ for the $\mathrm{pH}$ profile was determined by dividing the specific activity at a given $\mathrm{pH}$ by that at a $\mathrm{pH} 7.5$ in sodium phosphate buffer.

To investigate the inhibitory effect of released xylose on XynB activity, increasing concentrations of xylose (up to $150 \mathrm{mM}$ ) in $50 \mathrm{mM}$ sodium phosphate buffer at $\mathrm{pH} 7.0$ was added to each well in the pNPX assay. The relative activity of XynB at different concentrations of xylose was calculated by dividing the specific activity at a given concentration of xylose by that of control reaction without xylose.

\section{Effect of $\mathrm{pH}$ and Temperature on Activity}

The optimal $\mathrm{pH}$ for XynA was determined by performing the DNS assay in $50 \mathrm{mM}$ sodium citrate buffer for $\mathrm{pH} 4.5-6.0$ and $50 \mathrm{mM}$ sodium phosphate buffer for $\mathrm{pH}$ 6.0-8.0. The optimal temperature for XynA was determined in $50 \mathrm{mM}$ sodium citrate buffer (pH 6.0) at temperatures ranging from 30 to $70{ }^{\circ} \mathrm{C}$. The optimal $\mathrm{pH}$ for $\mathrm{XynB}$ was determined by pNPX assay using the same buffer and $\mathrm{pH}$ range that was used for XynA. The optimal temperature for XynB was determined in $50 \mathrm{mM}$ sodium phosphate buffer $(\mathrm{pH} 7.0)$ in temperatures ranging from 22 to $70^{\circ} \mathrm{C}$.

\section{Synergy of Xylanase and $\beta$-Xylosidase on Xylan Hydrolysis}

The synergism between XynA and XynB was investigated by combining crude enzymes in $1: 1,1: 2$, and $1: 3$ ratios with an equal volume of $1 \%$ beech wood xylan prepared in $50 \mathrm{mM}$ sodium phosphate buffer ( $\mathrm{pH}$ 7.0). A reference reaction was also set up in a similar way using $\mathrm{XynA}$ alone. The mixture was incubated at $40{ }^{\circ} \mathrm{C}$ for $16 \mathrm{~h}$ and the collected samples were examined by HPLC (1100 series, Agilent Technologies) with a RAO organic acid column. $0.0025 \mathrm{M} \mathrm{H}_{2} \mathrm{SO}_{4}$ was used as the mobile phase, $5 \mu \mathrm{L}$ of each sample was injected into the system with a flow rate of $0.3 \mathrm{~mL} / \mathrm{min}$, and the column was run at $60{ }^{\circ} \mathrm{C}$.

\section{Results and Discussion}

Cloning and Expression of Recombinant Xylanase and $\beta$-Xylosidase

Amplification of xylanase and $\beta$-xylosidase genes from $B$. subtilis M015 using specific primer pairs yielded 642 and 1602 bp DNA fragments, respectively. Complete sequencing of both strands of each fragment revealed that these genes are encoding for a protein of 213 amino acid residues for XynA (calculated MW of 23,358 Da) and a protein of 533 amino acid residues for XynB (calculated MW of 61,365 Da). The amino acid sequence of XynA was $100 \%$ identical 
to that of B. subtilis R5 (GenBank; AB457186) and $99 \%$ identical to that of B. subtilis subsp. subtilis 168 (AL009126.3, GeneID; 939861). The amino acid sequence of XynB was $100 \%$ identical to that of B. subtilis subsp. subtilis 168 (AL009126.3, GeneID; 939472) and $99 \%$ identical to that of B. subtilis BSP1 (GenBank, CP003695). These findings confirm that XynA belongs to the glycoside hydrolase $(\mathrm{GH})$ family 11 whereas XynB belongs to GH family 43.

The maximum activities of the crude enzymes were determined as $2.75 \pm 0.30 \mathrm{IU} / \mathrm{mL}$ and $0.41+/-0.02 \mathrm{IU} / \mathrm{mL}$ for XynA and XynB, respectively. Both XynA, which was purified and concentrated using centrifugal filters (Millipore), and XynB were visualized on a $12 \%$ sodium dodecyl sulfate polyacrylamide gel electrophoresis (SDS-PAGE) gel stained with Coomassie Blue (Biorad) and had molecular weights of approximately 20 and $60 \mathrm{kDa}$, respectively (Fig. 1), consistent with their theoretical molecular weights.

\section{Xylanase Enzymatic Characteristics}

The characteristics of the recombinant xylanase were determined using beech wood xylan as the substrate. The temperature and $\mathrm{pH}$ profile of XynA can be found in Fig. 2a, b. As with many xylanases previously described, XynA prefers mesophilic and slightly acidic conditions. Under the assay conditions used in our study, XynA displayed optimum activity at $50{ }^{\circ} \mathrm{C}$ while retaining over $50 \%$ relative activity between 37 and $60{ }^{\circ} \mathrm{C}$. Unlike other xylanases of B. subtilis CXJZ [19] and B. subtilis cho40 [13], XynA has a lower optimum temperature, making it very similar to xylanases of B. subtilis B-10 [20] and B. subtilis R5 [21] whose sequence is identical to XynA (optimum temperature reported as 40 to $50{ }^{\circ} \mathrm{C}$ ). XynA performed optimally in sodium citrate buffer at $\mathrm{pH}$ 5.5-6.0; however, its activity quickly dropped below $\mathrm{pH} 5.0$ and when in sodium phosphate buffer of any $\mathrm{pH}$. The activity profile of XynA in sodium citrate buffer is consistent with xylanases from strains mentioned above including B. subtilis R5; however, unlike others, it displays much lower activity in phosphate buffer.

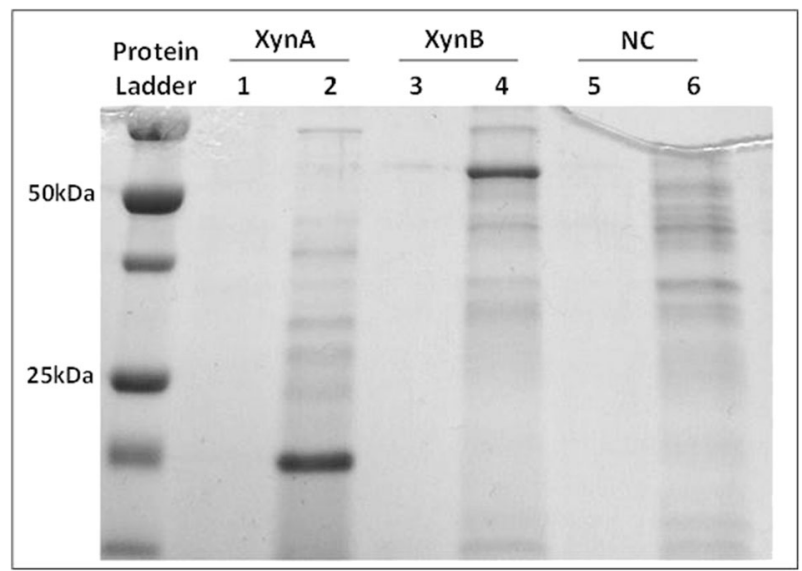

Fig. 1 SDS-PAGE of recombinant enzymes. Lanes 2 and 4 show dominant blue protein bands present in culture supernatants corresponding to recombinant XynA and XynB, respectively. ' $N C$ ' corresponds to E. coli JE5505 cells containing only pFLAG-CTS. Supernatant samples loaded to lanes 1, 3, and 5 were taken before inducing protein expression 

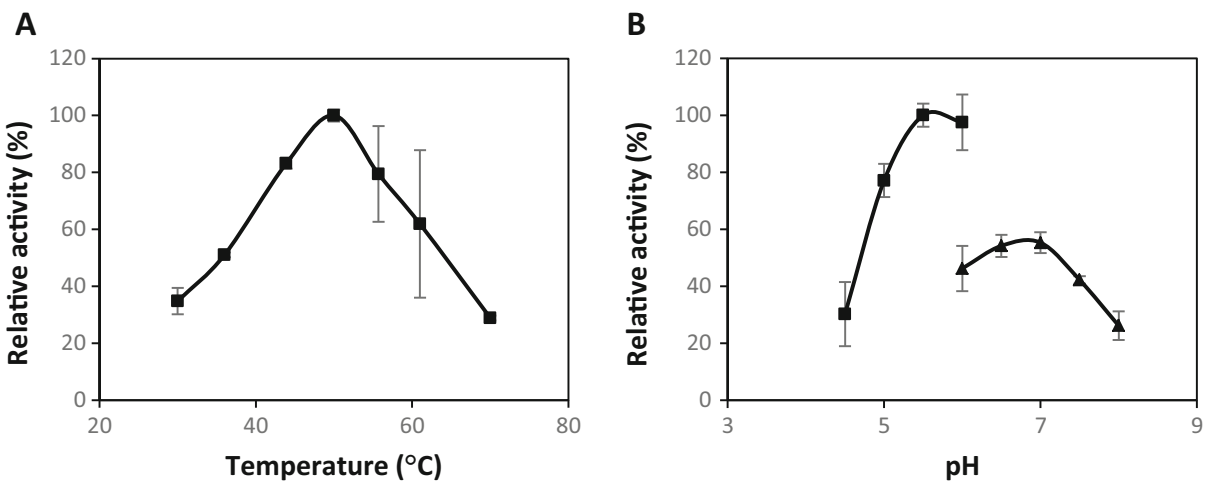

Fig. 2 Temperature and $\mathrm{pH}$ profiles of recombinant XynA. a. Effect of temperature on enzyme activity measured at $\mathrm{pH} 6.0$ in sodium citrate buffer (filled squares). b. Effect of $\mathrm{pH}$ on enzyme activity measured at $50{ }^{\circ} \mathrm{C}$ using sodium citrate buffer and sodium phosphate buffer (filled triangles). Error bars represent standard deviation of triplicate assays

\section{$\beta$-Xylosidase Enzymatic Characteristics}

We have characterized the xylosidase activity of recombinant XynB using pNPX as the substrate and its temperature and $\mathrm{pH}$ profiles are shown in Fig. 3a, b. The optimum temperature for $\mathrm{XynB}$ was determined as $35^{\circ} \mathrm{C}$. Its activity at $40{ }^{\circ} \mathrm{C}$, often the optimum temperature for GH43 $\beta$-xylosidases isolated from bacteria, drops to around $75 \%$ relative to its activity at $35^{\circ} \mathrm{C}$. The temperature used to determine xylosidase activity varies greatly in literature for $\beta$ xylosidases of Bacillus spp.; $25^{\circ} \mathrm{C}$ for B. subtilis subsp. subtilis 168 [22], $30{ }^{\circ} \mathrm{C}$ for B. subtilis PAP115 [23], and $50{ }^{\circ} \mathrm{C}$ for B. subtilis (subspecies not reported) [24]. Therefore, XynB's optimum temperature falls within the range of closely-related $\beta$-xylosidases. Similar to its temperature profile, XynB's optimum $\mathrm{pH}$ of 7.0 agrees with the $\mathrm{pH}$ profile of most GH-43 $\beta$ xylosidases [22-24]. XynB showed highest activity in sodium phosphate buffer at $\mathrm{pH} 7.0-7.5$ but dropped to a relative activity of around $20 \%$ at $\mathrm{pH}$ 6.0. Interestingly, we have observed that, besides its xylosidase activity, XynB also displays lower galactosidase activity when

A

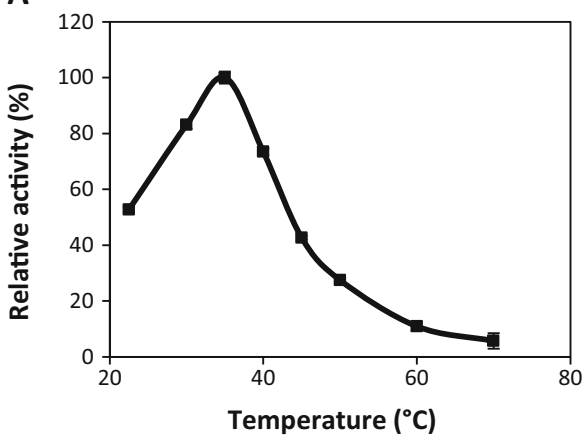

B

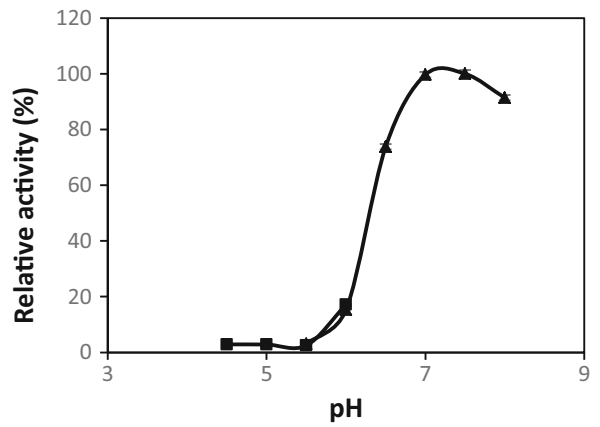

Fig. 3 Temperature and $\mathrm{pH}$ profiles of recombinant XynB. a. Effect of temperature on enzyme activity measured at pH 7.5 in sodium citrate buffer (filled squares). b. Effect of $\mathrm{pH}$ on enzyme activity measured at $35^{\circ} \mathrm{C}$ using sodium citrate buffer and sodium phosphate buffer (filled triangles). Error bars represent standard deviation of triplicate assays 
tested with 2-nitrophenyl- $\beta$-galactopyranoside (oNPGal) but no glucosidase activity was detected when tested with 4-nitrophenyl- $\beta$-glucopyranoside (pNPG) (unpublished results).

Previous studies have shown that some $\beta$-xylosidases experience end-product inhibition by xylose present in the reaction mix $[15,25]$. We have observed a similar effect on XynB where its relative activity quickly dropped to $55 \%$ in the presence of $20 \mathrm{mM}$ of xylose and continued decreasing with increasing xylose concentration in the reaction mix (Fig. 4). However, this should not present an issue for consolidated bioprocesses with fuel-producer strains wherein xylose is consumed before it accumulates to inhibitory concentrations.

\section{Synergy of Xylanase and $\beta$-Xylosidase on Xylan Hydrolysis}

To investigate the co-activity of XynA and XynB, varying ratios of two enzymes were incubated with beech wood xylan and produced oligosaccharide profiles were determined by HPLC. When tested alone, XynA released mostly xylobiose and to a lesser amount, xylotriose and xylotetraose; but no xylose was detected in the samples. The combination of $\mathrm{XynA}$ and XynB, however, allowed for the production of xylose as well as increased amounts of all xylooligosaccharides examined (xylose, xylobiose, xylotriose, and xylotetraose) as seen in Fig. 5.

In particular, combining the two enzymes in a 1:3 volume ratio released the most sugar from xylan over $16 \mathrm{~h}$ incubation. After an incubation of only $1 \mathrm{~h}$, the XynA/XynB combination increased the total amount of sugars released by about $20 \%$ with xylobiose being the primary sugar released. By $16 \mathrm{~h}$, the total amount of sugars released was about $90 \%$ higher than that of XynA alone again with the primary sugar as xylobiose. A similar synergistic effect was noticed by Carapito et al. (2009), Bao et al. (2012), and Zhou et al. (2012) who also reported that the combination of the two enzymes led to xylose formation with an excess of xylobiose [16, 26, 27]. It should be noted here that, although a standard for xylopentaose was not included in this study, the increase in the peak for LB media indicates that the hydrolysis of xylan with XynA/XynB complex leads to formation of another product, possibly xylopentaose, whose peak being overlapped by that of growth media.

In conclusion, we have successfully isolated and expressed the genes encoding for endoxylanase and $\beta$-xylosidase of $B$. subtilis M015 in E. coli JE5505 and characterized their activity in xylan hydrolysis. The compatibility of optimum reaction conditions and their

Fig. 4 Inhibition of XynB by xylose. Error bars represent standard deviation of triplicate assays

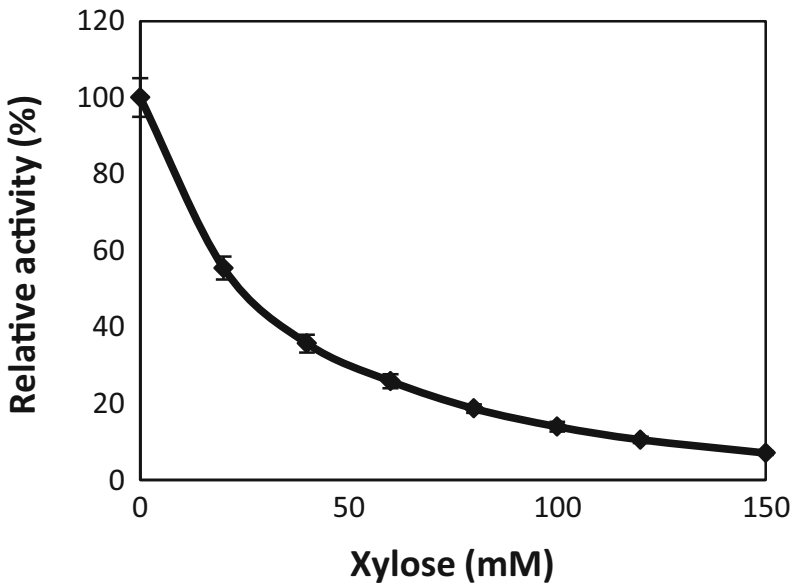


A

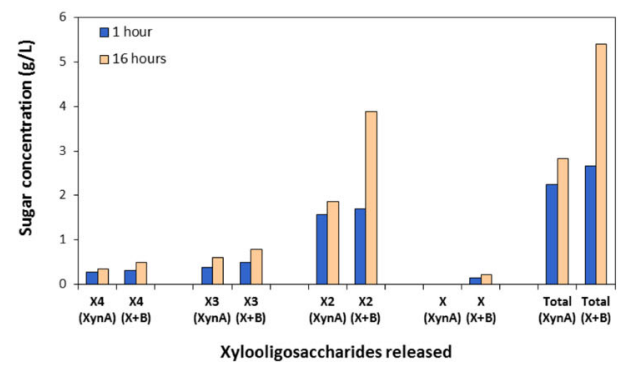

B

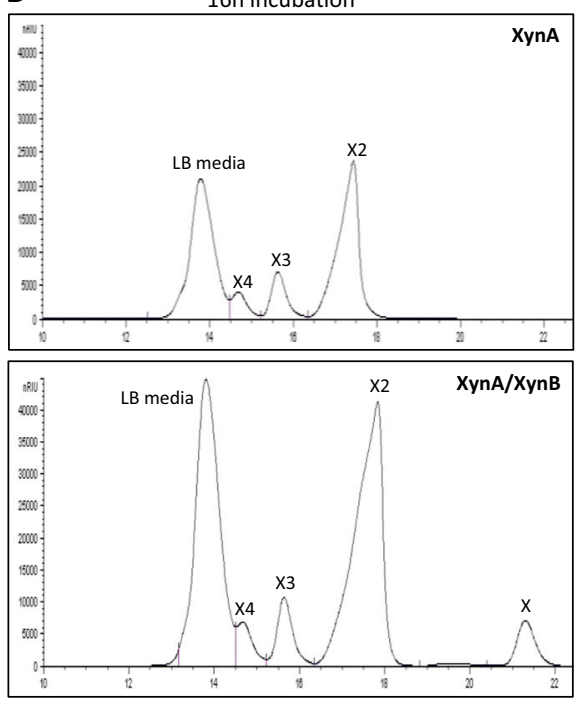

Fig. 5 Xylan hydrolysis by XynA and XynA/XynB (at 1:3 ratio) a. Amount of different sugars released at 1 and $16 \mathrm{~h}$ incubation (determined by DNS assay) b. HPLC diagram of xylan hydrolysis by XynA (top) and XynA/ XynB (bottom) after $16 \mathrm{~h}$ incubation. $X+B$ XynA + XynB, $X 4$ xylotetrose, $X 3$ xylotriose, $X 2$ xylobiose, and $X$ xylose

consequently high synergistic activity makes them compatible with bacterial cultivation and will allow these clones to be used in a consolidated bioprocess with a fuel-producer strain to convert xylooligosaccharides into biofuels (i.e., ethanol, isobutanol, etc.) by using xylan as the feedstock.

Acknowledgments We would like to acknowledge the help of Dr. Alissa Kerner and Dr. Jeremy Minty from Professor Xiaoxia Lin's Lab at the Department of Chemical Engineering, University of Michigan. Partial funding of this project by the Gates foundation and College of Engineering is gratefully acknowledged.

Open Access This article is distributed under the terms of the Creative Commons Attribution License which permits any use, distribution, and reproduction in any medium, provided the original author(s) and the source are credited.

\section{References}

1. Simmons, B. A. (2011). Opportunities and challenges in advanced biofuel production: the importance of synthetic biology and combustion science. Biofuels, 2(1), 5-7.

2. Bokinsky, G., Peralta-Yahya, P. P., George, A., Holmes, B. M., Steen, E. J., Dietrich, J., Lee, T. S., TullmanErcek, D., Voigt, C. A., Simmons, B. A., \& Keasling, J. D. (2011). Synthesis of three advanced biofuels from ionic liquid-pretreated switchgrass using engineered Escherichia coli. Proceedings of the National Academy of Sciences of the United States of America, 108(50), 19949-19954.

3. Hildebrand, A., Schlacta, T., Warmack, R., Kasuga, T., \& Fan, Z. (2013). Engineering Escherichia coli for improved ethanol production from gluconate. Journal of Biotechnology, 168(1), 101-106.

4. Mattam, A. J., \& Yazdani, S. S. (2013). Engineering E. coli strain for conversion of short chain fatty acids to bioalcohols. Biotechnology for Biofuels, 6(1), 128.

5. Minty, J. J., Singer, M. E., Scholz, S. A., Bae, C. H., Ahn, J. H., Foster, C. E., Liao, J. C., \& Lin, X. N. (2013). Design and characterization of synthetic fungal-bacterial consortia for direct production of isobutanol 
from cellulosic biomass. Proceedings of the National Academy of Sciences of the United States of America, $110,14592-14597$.

6. Lee, D., Owens, V. N., Boe, A., \& Jeranyama, P. (2007). Composition of herbaceous biomass feedstocks, Plant Science Department. Brookings: South Dakota State University.

7. Oteino, D. O., \& Ahring, B. K. (2012). The potential for oligosaccharide production from the hemicellulose fraction of biomasses through pretreatment processes: xylooligosaccharides (XOS), arabinooligosaccharides (AOS), and mannooligosaccharides (MOS). Carbohydrate Research, 360, 84-92.

8. Scheller, H. V., \& Ulvskov, P. (2010). Hemicelluloses. Annual Review of Plant Biology, 61, 263-289.

9. Gilbert, H. J., Stalbrand, H., \& Brumer, H. (2008). How the walls come crumbling down: recent structural biochemistry of plant polysaccharide degradation. Current Opinion in Plant Biology, 11, 338-348.

10. Pauly, M., Gille, S., Liu, L., Mansoori, N., de Souza, A., Schultink, A., \& Xiong, G. (2013). Hemicellulose biosynthesis. International Journal of Plant Biology, 238(4), 627-642.

11. Zhang, J., Siika-Aho, M., Puranen, T., Tang, M., Tenkanen, M., \& Viikari, L. (2011). Thermostable recombinant xylanases from Nonomuraea flexuosa and Thermoascus aurantiacus show distinct properties in the hydrolysis of xylans and pretreated wheat straw. Biotechnology for Biofuels, 4, 12.

12. Krengel, U., \& Dijkstra, B. W. (1996). Three-dimensional structure of Endo-1,4-beta-xylanase I from Aspergillus niger: molecular basis for its low pH optimum. Journal of Molecular Biology, 263, 70-78.

13. Khandeparker, R., Verma, P., \& Deobagkar, D. (2011). A novel halotolerant xylanase from marine isolate Bacillus subtilis cho40: gene cloning and sequencing. New Biotechnology, 28(6), 814-821.

14. Correa, J. M., Graciano, L., Abrahao, J., Loth, E. A., Gandra, R. F., Kadowaki, M. K., Henn, C., \& Simão, R. C. (2012). Expression and characterization of a GH39 beta-xylosidase II from Caulobacter crescentus. Applied Biochemistry and Biotechnology, 168(8), 2218-2229.

15. Yan, Q. J., Wang, L., Jiang, Z. Q., Yang, S. Q., Zhu, H. F., \& Li, L. T. (2008). A xylose-tolerant betaxylosidase from Paecilomyces thermophila: characterization and its co-action with the endogenous xylanase. Bioresource Technology, 88.

16. Carapito, R., Carapito, C., Jeltsch, J. M., \& Phalip, V. (2009). Efficient hydrolysis of hemicellulose by a Fusarium graminearum xylanase blend produced at high levels in Escherichia coli. Bioresource Technology, $100,845-850$.

17. Taechapoempol, K., Sreethawong, T., Rangsunvigit, P., Namprohm, W., Thamprajamchit, B., Rengpipat, S., and Chavedej, S. (2010). Cellulase-producing bacteria from Thai higher termites, Microcerotermes sp. Enzymatic activities and ionic liquid tolerance, Applied Biochemistry and Biotechnology.

18. Miller, G. L. (1959). Use of dinitrosalicylic acid reagent for determination of reducing sugar. Analytical Chemistry, 31, 426-428.

19. Guo, G., Liu, Z., Xu, J., Liu, J., Dai, X., Xie, D., Peng, K., Feng, X., Duan, S., Zheng, K., Cheng, L., \& Fu, Y. (2012). Purification and characterization of a xylanase from Bacillus subtilis isolated from the degumming line. Journal of Basic Microbiology, 52(4), 419-428.

20. Huang, J., Wang, G., \& Xiao, L. (2006). Cloning, sequencing, and expression of the xylanase gene from a Bacillus subtilis strain B10 in Escherichia coli. Bioresource Technology, 97(6), 802-808.

21. Jalal, A., Rashid, N., Rasool, N., \& Akhtar, M. (2009). Gene cloning and characterization of a xylanase from a newly isolated Bacillus subtilis strain R5. Journal of Bioscience and Bioengineering, 107(4), 360-365.

22. Jordan, D. B., Wagschal, K., Grigorescu, A. A., \& Braker, J. D. (2013). Highly active beta-xylosidases of glycoside hydrolase family 43 operating on natural and artificial substrates. Applied Microbiology and Biotechnology, 97, 4415-4428.

23. Bernier, R., \& Desrochers, M. (1985). Molecular-cloning of a beta-xylosidase gene from Bacillus subtilis. Journal of General and Applied Microbiology, 31, 513-518.

24. Bernier, R., Desrochers, M., Paice, M. G., \& Yaguchi, M. (1987). Isolation and characterization of beta-xylosidase from a recombinant Escherichia coli strain. Journal of General and Applied Microbiology, 33, 409-419.

25. Chen, Z., Jia, H., Yang, Y., Yan, Q., Jiang, Z., \& Teng, C. (2012). Secretory expression of a beta-xylosidase gene from Thermomyces lanuginosus in Escherichia coli and characterization of its recombinant enzyme. Letters in Applied Microbiology, 55(5), 330-337.

26. Bao, L., Huang, Q., Chang, L., Sun, Q., Zhou, J., \& Lu, H. (2012). Cloning and characterization of two betaglucosidase/xylosidase enzymes from yak rumen metagenome. Applied Biochemistry and Biotechnology, $166,72-86$.

27. Zhou, J., Bao, L., Chang, L., Liu, Z., You, C., \& Lu, H. (2012). Beta-xylosidase activity of a GH3 glucosidase/xylosidase from yak rumen metagenome promotes the enzymatic degradation of hemicellulosic xylans. Letters in Applied Microbiology, 54, 79-87. 